\title{
On the Quantitative Evaluation of Adiabatic Shear Banding Sensitivity of Various Titanium Alloys
}

\author{
C. Mazeau, L. Beylat, P. Longère and P.F. Louvigné \\ DGADCE/CREA, Materials under Severe Conditions Department, 16 bis avenue Prieur de la Côte d'Or, \\ 94114 Arcueil cedex, France
}

\begin{abstract}
Titanium alloys exhibit attractive ballistic performances due to their low density and their high mechanical properties. They are unfortunately very sensitive to adiabatic shear localization. This study aims to determine an empirical parameter which allows to characterise the sensitivity to the adiabatic shear banding of different grades of titanium alloys. Dynamic punching tests by split Hopkinson pressure bar are performed on disc shaped specimen to obtain shear bands.

This article deals with the possibility to size different materials according to their sensitivity to wiabatic shear on a defined scale with a such simple test.
\end{abstract}

\section{RESUME}

\begin{abstract}
Alliant hautes performances mécaniques et faible densité, les alliages de titane semblent être de bons candidats pour des applications de blindage. Néanmoins, ils sont très sensibles au cisaillement adiabatique, mode de ruine très fréquemment rencontré lors de la perforation d'une cible. L'objet de cette étude est de déterminer un paramètre empirique capable d'identifier la sensibilité au cisaillement adiabatique d'alliages de titane. Des tests de poinçonnage dynamique par barres d'Hopkinson, permettant d'obtenir des bandes de cisaillement sur des disques, sont effectués. La perspective qu'offre un tel test d'établir un classement des différents matériaux sur une échelle de sensibilité est discutée.
\end{abstract}

\section{INTRODUCTION}

Adiabatic shear banding has been clearly identified as an important mode of deformation at high strain rates [ 1 , $2,3]$. Then it plays an important role during armour perforation $[4,5]$. The thermomechanical environment necessary to form this plastic instability is now established [1]. Adiabatic Shear Band (ASB) has been defined as a stress localization phenomenon generally caused by a plastic instability causing by thermal softening during adiabatic or quasi-adiabatic deformation.

The list of the physical and mechanical factors which have an influence on this process is now also quite exhaustive $[1,6]$. Moreover, numerous studies in theorical analysis $[3,7]$ and numerical simulation have been achieved in order to define a threshold criterion of the instability initiation. The difficulty of these last studies remains in the lack of experimental data (temperature range..) of this process, eventhough some improvements are realised in this domain [8,9]. More particularly, during the last decade, the knowledge of the microstructure in the ASB, was greatly improved by a lot of post-mortem examinations, especially by transmission electron microscopy $[2,10,11 \& 12]$. Then the exact physical phenomenon is not still clearly understood.

Then many criterions were proposed to predict the Adiabatic Shear Banding Sensitivity (ASBS) and initiation. These criterions are difficult to use, because they need the experimental determination of several mechanical and physical parameters. Moreover they do not often lead to the same conclusions when these models are utilised to compare different materials because of the differences between the criterions [7].

This study aims to propose an empirical parameter taking into account an experimental average value of the localization energy. Afterwards this parameter would be very useful to size titanium alloys in according to ASBS, thus it allows the best choice of a material for ballistic application.

Several grades of titanium alloys, which have different chemical compositions and different initial microstructures, are investigated. The mechanical and physical properties of the different grades are firstly determined in order to use a maximal shear stress criterion similar to Culver 's one [1]. On the other hand dynamic punching tests are performed on disc shaped specimens. The different damages induced in the specimen are determined by an optical microscopic examination. Experimental data from dynamic punching test are analysed in order to access to the disc loading and indentor displacement histories. Information allows to calculate an average value of the localization energy. The possibility to establish a size order of material according to the ASBS with such a simple test is finally developed. 


\section{MATERIALS}

One commercial purity titanium (Ti 40) and three titanium alloys (one Ti $20 \% \mathrm{~V} 4.5 \% \mathrm{Al}$; two Ti $6 \% \mathrm{Al} 4 \% \mathrm{~V}$; and three $\mathrm{Ti} 6 \% \mathrm{Al} 4 \% \mathrm{Zr} 3 \% \mathrm{Mo} 2 \% \mathrm{Cr} 2 \% \mathrm{Sn} 1 \% \mathrm{Fe}$ ) are studied. They have different microstructures which lead to different mechanical properties.

\section{1- Microstructures}

The microstructures of the different grades of titanium are given in the table I and three examples of these different microstructures are presented in the figure 1.

Table I: microstructures of the different grades of titanium

\begin{tabular}{|c|c|}
\hline materials & microstructures \\
\hline $\mathrm{Ti} 40$ & equiaxed $\alpha$ [13] grains with mean grain size about $45 \mu \mathrm{m}$. (fig.1.a) \\
\hline Ti $20 \mathrm{~V} 4.5 \mathrm{Al}$ & equiaxed $\beta$ [13] grains with mean grain size about $220 \mu \mathrm{m}$. \\
\hline A/Ti $6 \mathrm{Al} 4 \mathrm{~V}$ & equiaxed $\alpha$ grains in a $\beta$ matrix. The mean $\alpha$ grain size is about $10 \mu \mathrm{m}$. (fig. $1 . b$ ) \\
\hline $\mathrm{B} / \mathrm{Ti} 6 \mathrm{Al} 4 \mathrm{~V}$ & equiaxed $\alpha$ grains in a $\alpha \beta$ matrix. The mean $\alpha$ grain size is about $10 \mu \mathrm{m}$. \\
\hline ATi $6 \mathrm{Al} 4 \mathrm{Zr} 3 \mathrm{Mo} 2 \mathrm{Cr} 2 \mathrm{Sn}$ IFe & $\begin{array}{l}\text { bimodal structure with } \alpha \text { phase and } \beta \text { phase [13]. The mean } \alpha \text { grain size is about } \downarrow \mu \mathrm{m} \text {; Uic a } \\
\text { platelet diameter is about } 0.70 \mu \mathrm{m} \text { and its length is about } 4 \mu \mathrm{m} \text {. (figl.c) }\end{array}$ \\
\hline $\mathrm{B} / \mathrm{Ti} 6 \mathrm{Al} 4 \mathrm{Zr} 3 \mathrm{Mo} 2 \mathrm{Cr} 2 \mathrm{Sn} \mathrm{IFe}$ & $\begin{array}{l}\text { bimodal structure with } \alpha \text { p. } \alpha \text { s phases and } \beta \text { phase [13]. The mean } \alpha \text { grain size is about ' } 1 \text { trit: } \\
\text { the } \alpha \text { platelet diameter is about } 0.60 \mu \mathrm{m} \text { and is length is about } 4 \mu \mathrm{m} \text {. }\end{array}$ \\
\hline CrTi $6 \mathrm{Al} 4 \mathrm{Zr} 3 \mathrm{Mo} 2 \mathrm{Cr} 2 \mathrm{Sn} 1 \mathrm{Fe}$ & lamellar suructure with $\alpha$ p. $\alpha$ s phases and $\beta$ phase [13]. \\
\hline
\end{tabular}

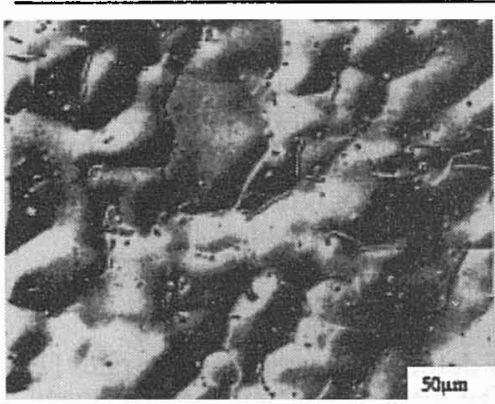

fig. I.a) Ti 40

equiaxed $\alpha$ grains

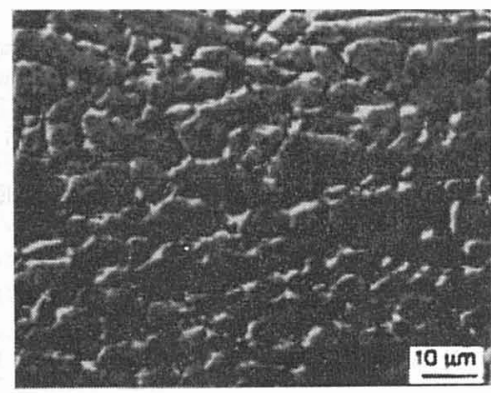

fig. 1.b) ArTi $6 \mathrm{Al} 4 \mathrm{~V}$ equiaxed $\alpha$ grains in a $\beta$ matrix

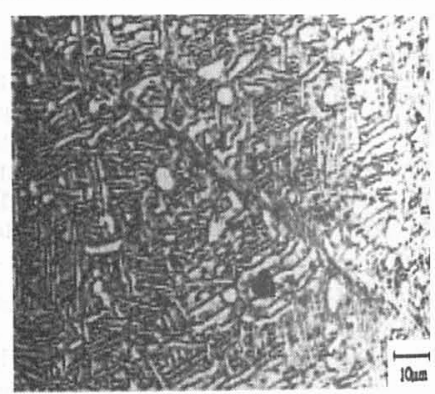

tigg. 1.c) A/Ti $6 \mathrm{Al} 4 \mathrm{Zr} 3 \mathrm{Mo} 2 \mathrm{Cr} 2 \mathrm{Sn}$ IF: bimodal structure with two phases

ligure 1 : optical micrographs showing different initial microstructures.

\section{2- Thermal and mechanical properties}

The specific heat $(\mathrm{Cp})$, which is measured by differential calorimetry, is presented in the table II.

The thermal conductivity $(K)$, which is determined from the equation $K=a . p . C p$ where $a$ is the thermal diffusivity which is measured by the method of modulated incident laserbeam, is presented in the table II.

The mechanical properties are determined for each grade of titanium. Tensile and compressive tests are realised at low and high strain rate (respectively $10^{-3} \mathrm{~s}^{-1}$ and $10^{3} \mathrm{~s}^{-1}$ ) at room temperature.

The quasi-static yield stress $\left(\mathrm{Rp}_{0,2}\right)$ and the total clongation $(\mathrm{A} \%)$ are given in the table II.

Table II : thermal propertics and static tensile characteristics

\begin{tabular}{cccccc}
\hline materials & $\begin{array}{c}\text { density } \rho \\
(\mathrm{kg} / \mathrm{m} 3)\end{array}$ & $\begin{array}{c}\text { specific heat Cp } \\
(\mathrm{J} / \mathrm{kg} \cdot \mathrm{K})\end{array}$ & $\begin{array}{c}\text { thermal conductivity K } \\
(\mathrm{W} / \mathrm{m} . \mathrm{K})\end{array}$ & $\begin{array}{c}\mathrm{R}_{\mathrm{p} 0.2} \\
(\mathrm{MPa})\end{array}$ & $\begin{array}{c}\mathrm{A} \\
(\%)\end{array}$ \\
\hline Ti 40 & 4560 & $510 \pm 50$ & 19 & 280 & $\geq 20$ \\
Ti 20V 4.5Al & 4640 & $550 \pm 10$ & 6.3 & $587 \pm 3$ & 26.4 \\
A/Ti 6Al 4V & 4460 & $590 \pm 20$ & 3.2 & $837 \pm 0$ & 16 \\
B/Ti 6Al 4V & 4460 & $540 \pm 20$ & 7.5 & $910 \pm 3$ & 15 \\
A/Ti 6Al 4Zr 3Mo 2Cr 2Sn IFe & 4720 & $500 \pm 10$ & 6.3 & $1022 \pm 15$ & 13 \\
B/Ti 6Al 4Zr 3Mo 2Cr 2Sn 1Fe & 4720 & $520 \pm 25$ & 6.3 & $1210 \pm 10$ & 9.3 \\
C/Ti 6Al 4Zr 3Mo 2Cr 2Sn 1Fe & 4720 & $520 \pm 10$ & 6.7 & $1095 \pm 13$ & 4.7 \\
\hline
\end{tabular}

The addition of chemical element as Al and so on provokes an important decrease of the thermal conductivity. which is already low for titanium.

The increase of the yield stress $(\mathrm{Rp} 0,2)$ provokes a decrease of the total elongation $\left(A, D_{0}\right)$ 


\subsection{Behaviour model and instability criterion}

The Johnson-Cook power-law is used in order to describe materials behaviour in compression :

$$
\sigma=\left(\sigma_{0}+k \cdot \varepsilon^{n}\right) \cdot\left(1+c \cdot \ln \dot{\varepsilon}^{*}\right) \cdot\left(1-\mathrm{T}^{* m}\right) \quad \text { where } \mathrm{T}^{*}=\frac{\mathrm{T}-\mathrm{T}_{\text {room }}}{\mathrm{T}_{\text {melt }}-\mathrm{T}_{\text {room }}} \text { and } \quad \dot{\varepsilon}^{*}=\frac{\dot{\varepsilon}}{\dot{\varepsilon}_{\mathrm{u}}}
$$

The different parameters calculated from this law are shown in the table III.

The condition of adiabatic shear band initiation is usually given by a critical plastic strain criterion. In order to predict the critical instability strain, a modified form of Johnson-Cook constitutive model is used (2). A similar analysis to Lindholm-Johnson 's one [1] leads to (3).

$\sigma=\left(\sigma_{0}+k \cdot \varepsilon^{n}\right) \cdot\left(1+c \cdot \ln \dot{\varepsilon}^{*}\right) \cdot(1-b \cdot T)$

$$
\varepsilon_{\mathrm{i}}=\frac{\mathrm{n} \cdot \mathrm{p} \cdot \mathrm{C}_{\mathrm{p}}}{\text { b. } \beta \cdot\left(\sigma_{0}+\mathrm{k}\right)}-\frac{\sigma_{0}}{\mathrm{k}} \cdot \varepsilon_{\mathrm{i}}^{1-\mathrm{n}}
$$

The "b" parameter and the critical instability strain are calculated and are presented in the table III.

\begin{tabular}{|c|c|c|c|c|c|c|c|c|}
\hline materials & direction & $\begin{array}{c}\sigma_{0} \\
(\mathrm{MPa})\end{array}$ & $\begin{array}{c}\mathrm{k} \\
(\mathrm{MPa})\end{array}$ & $\mathrm{n}$ & c & m & b & $\begin{array}{r}\varepsilon_{\mathrm{i}} \\
(\%)\end{array}$ \\
\hline Ti 40 & L & 380 & 2000 & 0.9 & $10^{-2}$ & 1.8 & 0 & $\infty$ \\
\hline $\mathrm{Ti} 20 \mathrm{~V} 4.5 \mathrm{Al}$ & $\stackrel{\mathrm{L}}{\mathrm{ST}}$ & $\begin{array}{l}815 \\
840\end{array}$ & $\begin{array}{l}620 \\
670\end{array}$ & $\begin{array}{c}0.5 \\
0.45\end{array}$ & $\begin{array}{l}3.7 .10^{-2} \\
3.9 .10^{-2}\end{array}$ & $\begin{array}{l}0.5 \\
0.45\end{array}$ & $\begin{array}{c}2.10^{-4} \\
2.510^{-4}\end{array}$ & $\begin{array}{l}9.5 \\
6.5\end{array}$ \\
\hline A $T$ i $6 \mathrm{Al} 4 \mathrm{~V}$ & $\mathrm{~L}$ & 870 & 990 & 0.25 & $1.1 .10^{-2}$ & 1 & $5.10^{-4}$ & 37 \\
\hline \multirow[t]{2}{*}{$\mathrm{B} / \mathrm{Ti} 6 \mathrm{Al} 4 \mathrm{~V}$} & L & 1048 & $\begin{array}{l}990 \\
950\end{array}$ & $\begin{array}{c}0.34 \\
0.2\end{array}$ & $1.15 .10^{-2}$ & 0.8 & $8.10^{-4}$ & 12 \\
\hline & ST & 1055 & 760 & 0.32 & $1.5 \cdot 10^{-2}$ & 0.9 & $7.10^{-4}$ & 20 \\
\hline \multirow[t]{2}{*}{$\mathrm{A} / \mathrm{Ti} 6 \mathrm{Al} 4 \mathrm{Zr} 3 \mathrm{Mo} 2 \mathrm{Cr} 2 \mathrm{Sn} 1 \mathrm{Fe}$} & $\mathrm{L}$ & 1115 & 990 & 0.34 & $1.7 .10^{-2}$ & 0.65 & $1.6 .10^{-3}$ & 7 \\
\hline & ST & 1190 & 990 & 0.5 & $1.55 .10^{-2}$ & 0.6 & $1.7 .10^{-3}$ & 6 \\
\hline \multirow[t]{2}{*}{$\mathrm{B} / \mathrm{Ti} 6 \mathrm{Al} 4 \mathrm{Zr} 3 \mathrm{Mo} 2 \mathrm{Cr} 2 \mathrm{Sn} 1 \mathrm{Fe}$} & $\mathrm{L}$ & 1205 & 990 & 0.34 & $1.5 .10^{-2}$ & 0.7 & $1.1 .10^{-3}$ & 11 \\
\hline & ST & 1180 & 910 & 0.4 & $1.1 .10^{-2}$ & 0.7 & $10^{-3}$ & 14 \\
\hline \multirow[t]{2}{*}{$\mathrm{C} / \mathrm{Ti} 6 \mathrm{Al} 4 \mathrm{Zr} 3 \mathrm{Mo} 2 \mathrm{Cr} 2 \mathrm{Sn} 1 \mathrm{Fe}$} & $\mathrm{L}$ & 1130 & 970 & 0.36 & $1.32 .10^{-2}$ & 0.7 & $10^{-3}$ & 13.5 \\
\hline & $S T$ & 1150 & 830 & 0.34 & $1.25 .10^{-2}$ & 0.75 & $10^{-3}$ & 12 \\
\hline
\end{tabular}

Table III : longitudinal (L) and short transverse (ST) Johnson-Cook power-law parameters for $0<\varepsilon<0.2$ and $10^{-3}<\dot{\varepsilon}<10^{3} \mathrm{~s}^{-1}$

In the investigated range of strain and strain rate, $\mathrm{Ti} 40$ is very low-sensitive to the thermal softening and very high-sensitive to the strain hardening. Ti20V4,5Al is very sensitive to the thermal softening and to the strain rate. Ti6Al4V and Ti6Al4Zr3Mo2 Cr2Sn1Fe alloys have the same sensitivity to the strain hardening and to the the strain rate.

\section{3- EXPERIMENTAL PROCEDURE}

The punching test set-up used with the split Hopkinson pressure bar (SHPB) was designed at the laboratory by B. Deltort [8] to create shear bands with a perfect control of their length. Its principle is quite similar to Chou's set up [14]. Disc shaped specimens with $26 \mathrm{~mm}$ diameter and $2 \mathrm{~mm}$ thickness are tested. An advantage of this geometry is the absence of geometric defects on the faces which could be created during the machining. Such defects could induced the ASB appearance.

\section{1-Experiment}

The punching test set up used in this work is drawn in fig.3. It is inserted between the SHPB, the indentor is located at the end of the input bar and the backup ring at the end of the output bar. A projectile impacts with a controlled velocity the input bar and produces an incident stress wave inside the input bar. This finite wave travels through the input bar and when it meets the punching test device, one part is transmitted to the output bar and the other part is reflected inside the input bar. Numerical simulation with ABAQUS 2D code in explicit version has shown that a monodimensionnal analysis of the test could be utilised to calculate the shear stress $(\tau)$ and the penetration depth (u)in a first approximation.

$$
\left\{\begin{array}{l}
\tau=\frac{S_{\text {bar }}}{S_{\text {shcared ares }}} \cdot \sigma_{T}=\frac{D_{\text {bar }}^{2}}{4 \cdot D_{\text {indentor }} \cdot d_{\text {disc }}} \cdot \sigma_{T} \\
u=-\frac{2 \cdot C_{\text {bar }}}{E_{\text {bar }}} \cdot \int_{0}^{t} \sigma_{R} \cdot d \tau-\frac{\sigma_{T}}{E_{\text {indentor }}} \cdot d_{\text {indentor }}
\end{array}\right.
$$


where $D_{i}$ is the diameter, $d_{i}$ is the thickness, $C_{i}$ is the elastic waves celerity and $E_{i}$ is the Young modulus of $j$. element, $\sigma_{\mathrm{R}}$ and $\sigma_{\mathrm{T}}$ are the reflected and transmitted stresses inside the bars.

The shear stress-penetration depth curves for Ti 40 and Ti $20 \mathrm{~V} 4.5 \mathrm{Al}$ are represented in figure 4.

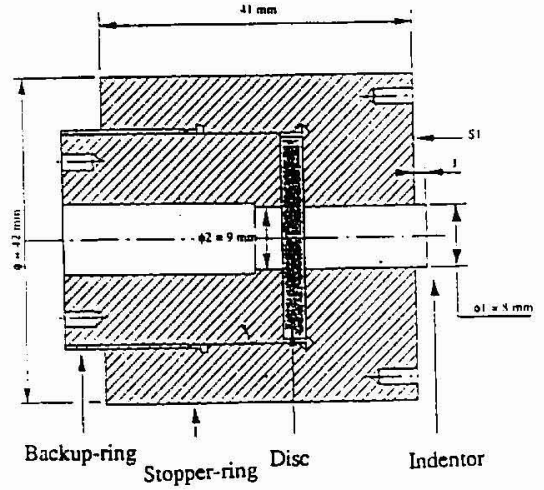

fig. 3 : Punching test device

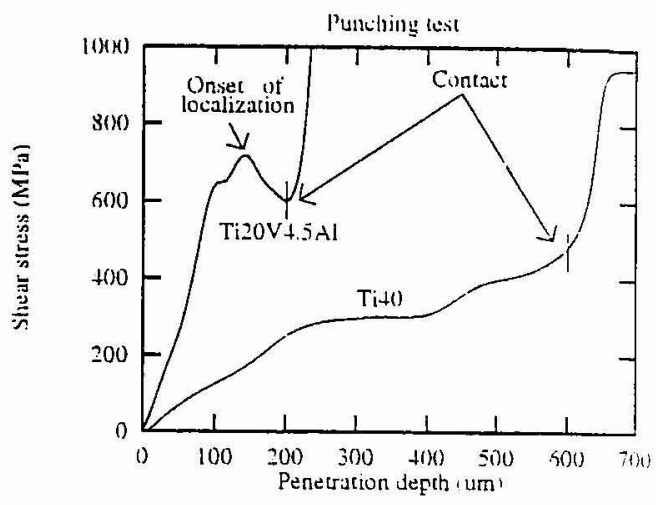

fig. 4 : shear stress versus penetration depth

The figure 4 shows that both materials give different answers in the same initial experimental conditions (specimen geometry and projectile impact velocity) : the shear stress of Ti40 answer is monotonic increasing, whereas the Ti20 V4.5Al shear stress increases, seems to reach a maximal value, and then decreases. It is assumed that this maximal shear stress value points out the onset of localization. A similar behaviour is also observed on Ti6Al4V and Ti6A14Zr3Mo2Cr2SnlFe. The last increase of the intensity of the shear stress is cause by the contact between the input bar and the device.

If the $\tau(\mathrm{u})$ curve presents a maximal value of intensity, an average value of localization energy can be expressed by :

$$
\mathrm{U}_{\text {loc }}=\int \mathrm{F} \cdot \mathrm{du}=\mathrm{S}_{\text {sheared ares }} \cdot \int_{0}^{\mathrm{u}\left(\tau_{\mathrm{mm}}\right)} \tau \cdot \mathrm{du}
$$

\section{2- Results}

The maximal shear stress and the localization energy values, which are determined with this punching test, are presented in the table IV.

table IV : maximal shear stress (MPa) and localization mean energy (J)

\begin{tabular}{cccc}
\hline materials & maximal shear stress (MPa) & localization energy (J) Uloc & tendency \\
\hline Ti 40 & $X$ & $X$ & 1 \\
Ti 20V 4,5Al & 715 & 2.97 & 2 \\
A/Ti 6Al 4V & 993 & 2.86 & 3 \\
B/Ti 6AI 4V & 832 & 2.24 & 4 \\
ATi 6Al 4Zr 3Mo 2Cr 2Sn 1Fe & 717 & 1.88 & 7 \\
BTi 6Al 4Zr 3Mo 2Cr 2Sn 1Fe & 705 & 1.74 & 6 \\
Cri 6Al 4Zr 3Mo 2Cr 2Sn 1Fe & 777 & 1.91 & 5 \\
\hline
\end{tabular}

After these tests, the discs are sectioned to be observed by optical microscope. The figure 9 shows very different examples of deformation area in different grades of titanium. 


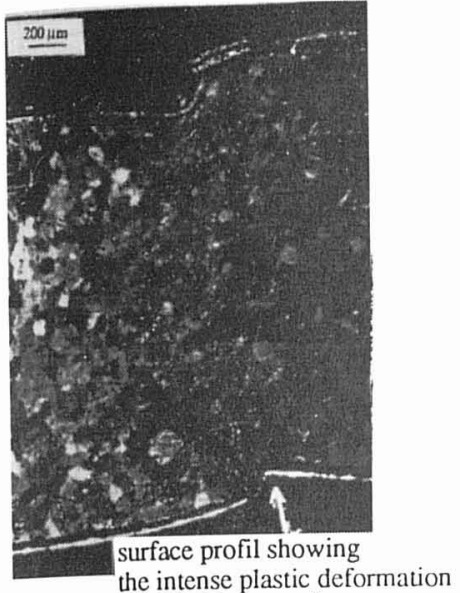

fig.9.a : Ti 40 - intense plastic

deformation evidenced without shear band

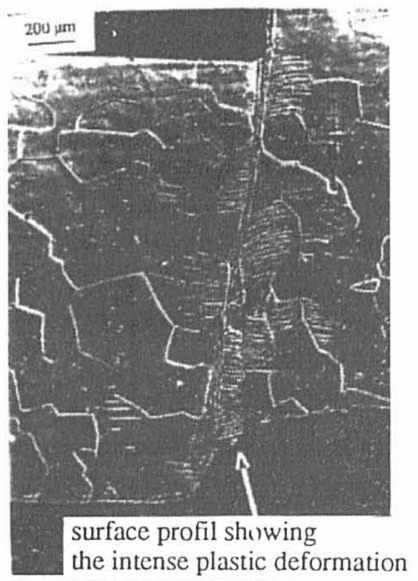

fig.9.b : Ti $20 \mathrm{~V} 4,5 \mathrm{Al}$ - intense plastic deformation with shear band

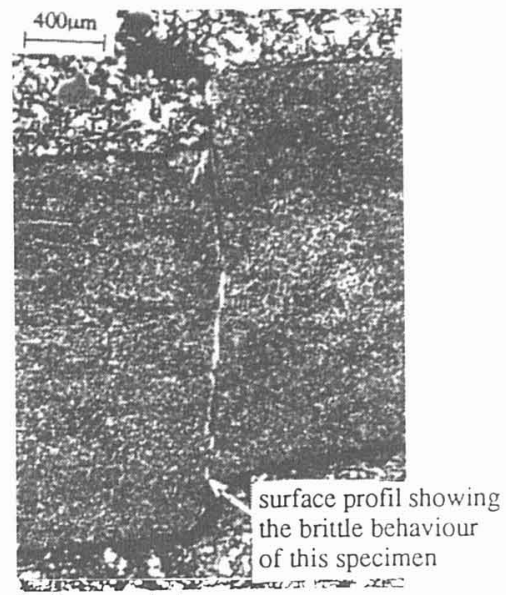

fig.9.c : A/Ti $6 \mathrm{Al} 4 \mathrm{Zr} 3 \mathrm{Mo} 2 \mathrm{Cr} 2 \mathrm{Sn} 1 \mathrm{Fe}$ - shear band without drastic homogenous plastic deformation

The whole titanium alloys present shear band except for the Ti 40 (figure 9.a), the shear stress-penetration depth curves present maximal shear stress values for all the titanium alloys and not for the commercial purity titanium. It is important to notice that Meyer [2] created in commercial purity titanium shear band. Then the mechanical interpretation agrees with microscopic examinations. Cracks in the shear band are always evidenced in titanium alloys. An intense plastic deformation is observed on several grades. It could be evidenced by the final shape of the back side (figure 9) and plastic defects like twins (figure 9.a).

From these results, it is possible to establish an ASB tendency (table IV), where Ti 40 is the least sensitive and $\mathrm{A} / \mathrm{Ti} 6 \mathrm{Al} 4 \mathrm{Zr} 3 \mathrm{Mo} 2 \mathrm{Cr} 2 \mathrm{Sn} 1 \mathrm{Fe}$ is the most sensitive. The size order between the three $\mathrm{Ti} 6 \mathrm{Al} 4 \mathrm{Zr}$ $3 \mathrm{Mo} 2 \mathrm{Cr} 2 \mathrm{Sn} 1 \mathrm{Fe}$ alloys is difficult to do at the present time.

\section{CONCLUSION}

As far as ballistic applications are concerned, it seems important that target materials spend the greatest energy by intense plastic deformation before localizing with adiabatic shear banding. Indeed this phenomenon often conduces to the catastrophic failure of the target material.

Simple punching tests are performed on disc shaped specimens in this study. This test allows to access to the mechanical behaviour of the material through a shear stress - penetration depth curve. If there is the appearance of shear band this curve exhibits a maximum $\left(\tau_{\max }\right)$. This maximal shear stress is plotted versus the tendency which is obtained by post-mortem examination. The critical instability strain $\left(\varepsilon_{\mathrm{i}}\right)$, which is based on the same assumption (maximal shear stress) is also plotted in this figure.

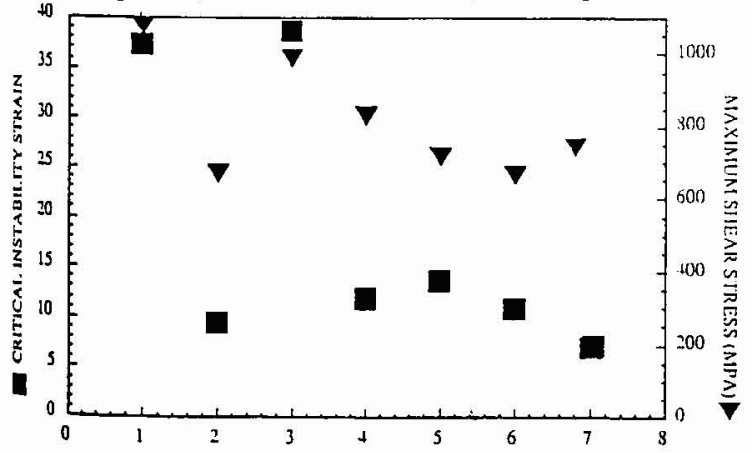

The maximal shear stress and the critical instability strain evolutions are quite similar and do not follow the size order tendency. The critical instability strain is not taking into account all the necessary parameters. This parameter is known as insufficient to predict the adiabatic shear banding appearance [6].

In order to take into account the homogenous plastic deformation, a localization energy value $\left(\mathrm{U}_{\mathrm{loc}}\right)$ is calculated from the maximal shear stress value.

This parameter is plotted versus the classification tendency in the figure 11 .

fig.10. : $\tau_{\max }$ and $\varepsilon_{\mathrm{i}}$ versus the size order obtained by postmortem examination 
It seems that materials size order which is defined with the localization energy is close to the postmortem examination one. Thus $U_{l o c}$ seems to be the best parameter to consider. In order to confirm furthermore this parameter choice, numerical simulation will allow to obtain a better understanding between experimental data and material answer. The influence of the loading time will also investigate. These researches would allow to confirm our materials size order. Thus the influence of the materials properties (chemical composition, initial microstructure, yield stress...) could be more particularly explained.

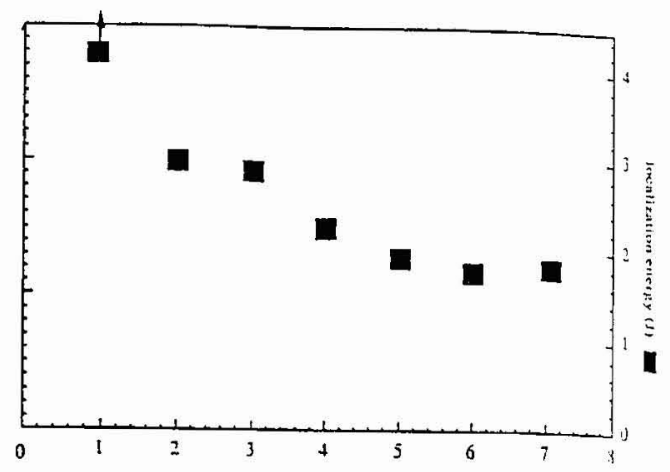

fig.11: Uloc and Rp0,2 versus the size order obtained by post-mortem examination

\section{REFERENCES}

[1] Y. Bai and B. Dodd, Adiabatic shear localization occurence, theories and applications, Pergamon Press. (1992)

[2] M.A. Meyers, G. Subhash, B.K. Kad, L. Prasad, Evolution of microstructure and shear- band formation in $\alpha$-hcp titanium, Mechanics of materials, 17 (1994) 175-193, Elsevier

[3] F. Dinzart, C. Fressengeas and A. Molinari, The catastrophic development of shear localization in thermoviscoplastic materials, C8-435-446, supplément au journal de physique III, vol. 4, (Sept 1994)

[4] Li Chen, Yong-chi Li and Li-li Wang, Analysis of adiabatic shear plugging of thermo-viscoplatic plates, Dymat journal, vol. 2, n³/4, Sep./Dec, (1995), 167-181

[5] R.L. Woodward, Int. J. Impact Engng 2, $121-129$

[6] R. Dormeval, I.P. Ansart, Cisaillement adiabatique: influence d'une prédéformation, Jour.Phys. coil C5, (1985), 46, pp. 299-306 (Dymat 85)

[7] J.R. Klepaczko, Some results and new experimental technique in studies of adiabatic shear bands, Arch. Mech., (1994),461-2 pp.201-229

[8] B. Deltort, Étude expérimentale et numérique du cisaillement adiabatique dans un acier martensitique, Thèse de l'Ecole supérieure des Mines de Paris, (22-12-93)

[9] A. Marchand \& J. Duffy, An experimental study of the formation process of adiabatic shear bands in a structural steel, J. Mech. Phys. Solids, (1988), 36, 59

[10] M.A. Meyers and Han-Ryong Pak, Observation of an adiabatic shear band in titanium by high-voltage transmission electron microscopy, Acta metall., (1986), vol. 34, n²12, pp. 2493-2499

[11] Y. Bai, Q. Xue, Y. Xu \& L. Shen, Characteristics and microstructure in the evolution of shear localization in Ti-6AI-4V alloy, Mechanics of materials, (1994), 17, 155-164

[12] J.A. Hines \& K.S. Vecchio, Recristallization kinetics within adiabatic shear bands, Acta mater., (1997), vol. $45, n^{\circ} 2$ pp $635-649$

[13] Y.Combres and B. Champin, Intégration des résultats de recherche dans les problèmes de fabrication des demi-produits en titane, La revue de Métallurgie-CIT/Science et Génie des Matériaux, (1996), pp1043-1055.

[14] P.C. Chou, J. Hashemi, A. Chou and H.C. Rogers, Experimentation and finite element simulation of adiabatic shear bands in controlled penetration impact, International Journal of Impact Engineering, (1991), vol. $11, \mathrm{n}^{\circ} 3$.

\section{ACKNOWLEDGMENTS}

The authors are grateful to Mrs Porcher and Mr Bégué for their technical assistances, and Mr Taladriz for his help in english. 